\title{
Assessment of patients' quality of life after haemorrhoidectomy using the LigaSure device
}

\author{
Robert Szyca ${ }^{1,2}$, Krzysztof Leksowski $^{1,2}$ \\ ${ }^{1}$ Department of General, Thoracic and Vascular Surgery, $10^{\text {th }}$ Military Clinical Hospital with Polyclinic, Bydgoszcz, Poland \\ ${ }^{2}$ Department of Public Health, Nicolas Copernicus University, Torun, Poland
}

Videosurgery Miniinv 2015; 10 (1): 68-72

DOI: $10.5114 /$ wiitm.2015.49672

\begin{abstract}
Introduction: Haemorrhoids are small anatomical structures within the anal canal that are involved in the proper functioning of the lower gastrointestinal tract. Factors favouring the development of haemorrhoidal disease are insufficient physical activity, prolonged sitting and hence a shortage of physical activity, as well as poor diet which lacks adequate amounts of fibre. The main symptom of this disease is bleeding with bright red blood just after defecation. Haemorrhoidal disease occurs when the ligamentous apparatus comes loose and the internal haemorrhoidal plexus translocates down, whereas haemorrhoids enlarge and move out of the anal canal. Haemorrhoidal disease treatment includes conservative, instrumental and surgical therapy.

Aim: To assess treatment and satisfaction in particular life domains after haemorrhoidectomy.

Material and methods: The research was undertaken in the General, Thoracic and Vascular Surgery Clinic of the $10^{\text {th }}$ Military Clinical Hospital with Polyclinic in Bydgoszcz among 50 patients treated due to haemorrhoids and operated on in the period 2007-2008. The study evaluated quality of patients' life after haemorrhoidectomy by Ferguson's method using a Ligasure appliance.

Results: The study investigated whether patients perceived a difference before and after surgery. The research proved that patients can describe disease symptoms and know the risk factors for haemorrhoids. In the studied group patients are able to describe characteristic signs of haemorrhoidal disease and also indicate differences in everyday life before and after the surgery. They can also describe and classify the pain before and 1 year after the haemorrhoidectomy, which was statistically significantly lower already 3 months after the operation.

Conclusions: Conducted examinations showed that sick people in the precise way were able to determine manifestations and know risk factors of the prevalence of disease hemorrhoidal. Operated sick people indicated the difference in quality of the life both before, as well as after the undergone treatment. After the operation of the haemorrhoids with method of Ferguson using LigaSure apparatus operated sick persons could distinguish and classify pain before the treatment as well as in a year after which was statistically characteristically lower already after three months from treatment.
\end{abstract}

Key words: quality of life, haemorrhoids, haemorrhoidectomy.

\section{Introduction}

Haemorrhoid disease is one of the most common diseases of the lowest part of the gastrointestinal tract, and related complications are often the cause of the provision of medical advice. Symptoms associated with haemorrhoids are experienced by $5 \%$ to $50 \%$ of the adult population. The common goal of all operative methods is to reduce the blood flow to the piles, partial obliteration of the haemorrhoidal

\section{Address for correspondence}

Robert Szyca MD, PhD, Department of General, Thoracic and Vascular Surgery, $10^{\text {th }}$ Military Clinical Hospital with Policlinics,

5 Powstańców Warszawy St, 85-651 Bydgoszcz, Poland, phone: +48 5237870 56, +48 $523787051,+48602470583$,

e-mail: robin22@poczta.onet.pl 
plexus and formation of a connective tissue scar which attaches the piles to the ground (underlying tissue) to prevent them from moving downwards. In spite of a wide range of surgical procedures of haemorrhoidal treatment applying different equipment and devices, none of them gives the certainty of success. There is some hope for further improvement in results of the treatment by using the LigaSure apparatus. This device is used with a satisfactory result for closing vessels in thyroid surgery, abdominal organs and chest. Currently in haemorrhoidal disease, we are working to develop operational methods which lead to minimal complaints of pain in the preoperative and postoperative period [1-15]. Instrumental methods for treatment of haemorrhoids are used in stages I and II, and more and more frequently in stages III and IV of the disease. The introduction of many new devices and use of different instrumental methods of treatment made it possible to shorten hospital stays, reduce the amount of complications (early and late), improve quality of life after haemorrhoidectomy and reduce the cost of the overall treatment. These methods are effective and safe. Instrumental treatment is not without the possibility of relapse, but considering its relatively low cost and low burden for the patient it is an alternative to classical surgery. The following methods of instrumental treatment are most often applied in contemporary surgery: sclerotherapy, cryotherapy, rubber garter method (Barron's method, called rubber band ligation), the combination of Barron' method and cryotherapy, photocoagulation and its combinations with Barron's method, electrocoagulation (monopolar, bipolar, LigaSure), haemorrhoidectomy using a harmonic knife, and others. In stages III and IV of the disease, still the method of choice is the surgical removal of the piles $[8,16-23]$. It is considered that the contemporary operation should be characterized by: a low recurrence rate, the ability to perform the surgery on an outpatient basis, and a rapid return of the patient to full professional activity after the surgery. In relation to applying in contemporary surgery many new devices and using different technologies, it is possible to modify traditional methods of operation. The modernization of electrosurgical instruments, which include the LigaSure, allows for the reduction of postoperative pain, and thus a faster return of the patients to normal activity is possible and it consequently improves their quality of life. Haemorrhoid surgery followed prevailing trends, and it is still in the phase of development and improvement. This applies to both the range of indications for surgery, improving existing surgical methods and continuous enrichment of instruments, and thus it leads to the development of new operating techniques. This will allow in the future to achieve better results of surgical treatment of haemorrhoidal disease. The operation of piles using the LigaSure device is technically simple. This method allows for precise removal of pathologically altered haemorrhoids and obtaining complete haemostasis in a short time. Mild pain after surgery allows for early discharge of patients from the hospital and a quick return to full activity in their work, which contributes to the improvement of the quality of life [19-26].

\section{Aim}

The purpose of the research was to assess the quality of life of patients after haemorrhoidectomy by Ferguson's method using the LigaSure apparatus. The subject of the study was subjective perception by patients of their state of health, both physical and mental health in the environment in which they live and work before and after the operation, as well as the intensity of the pain after the surgery.

\section{Material and methods}

The study was conducted among patients operated on in the Department of General, Thoracic and Vascular Surgery, $10^{\text {th }}$ Military Clinical Hospital with Polyclinic in Bydgoszcz (Poland) due to haemorrhoids in 2007-2008. The research involved a group of $50 \mathrm{pa}-$ tients aged 32 to 62 . The largest group consisted of patients aged 43-52 (27 people $-54 \%)$, followed by patients aged 53-62 (15 people $-30 \%$ ), then those aged 3242 (8 people $-16 \%$ ). Selection of the research group was made at random. Average age of women was 48 and men 51 years old. There were more women than men (42 females $-84 \%$ ). Most of the participants had secondary (34 people $-68 \%$ ) or higher education (17 people $-34 \%$ ). The vast majority of respondents $(86 \%)$ came from urban areas. Most were employed (37 people $-74 \%$ ), while pensioners formed a group of $8(16 \%)$ people. Most of the respondents were involved in sitting jobs (22 persons - 44\%), while $15(30 \%)$ patients had a standing job. There were $32(76.2 \%)$ women who had been pregnant and $16(43.8 \%)$ of them had been pregnant 
twice. Thirty-eight (76\%) of the patients were overweight. Our respondents used magazines, television and the internet as a source of knowledge about health and proper nutrition, and the majority of them (94\%) benefited from such knowledge.

For research we edited our own questionnaire form, a questionnaire to assess pain on the Numeric Rating Scale (NRS), and a questionnaire assessing the health and quality of life - EuroQol 4D. Surveys were voluntary.

\section{Statistical analysis}

Analysis of the collected material was carried quantitatively and qualitatively. In order to examine variation in characteristics and the occurrence of possible correlations, we used the $\chi^{2}$ test and analysis of variance (ANOVA). Furthermore, we applied a Spearman rank correlation. We adopted the level of significance $p \leq 0.05$.

\section{Results}

The most common problem that patients specified before surgery was the appearance of blood in the stool or donation immediately after defecation $(100 \%)$, a feeling of incomplete bowel movement also in $50(100 \%)$ people, and a feeling of anxiety and tension associated with their disease in $44(88 \%)$ people. The smallest problem, according to the respondents, was oozing secretion from the anal canal $(10 \%)$ and the occurrence of itching and burning in the perineum (20\%). Assuming a significance level of $p \leq 0.05$, the result of the emergence of filtration secretion from the anal canal is above the permitted level. Furthermore, the results concerning the appearance of blood in bowel movements and feeling of incomplete bowel movements are not statistically significant. It is essential that the state of health had not been allowed to perform household chores correctly by surveyed patients (92\%). Subsequently, it was specified: social life, meeting friends (84\%) and career (78\%). Least of all the health condition caused problems with sex life (36\%) as well as everyday life and family life (54\%). All evaluated indicators are within the specified range of the level of statistical significance $(p \leq 0.05)$. Health status improved, according to respondents to the greatest extent in carrying out household chores (92\%) and social life (86\%), followed by the performance of work $(80 \%)$ and everyday life (68\%). Health status in the sphere of sexual life improved in the smallest degree $(46 \%)$. Also in this case, the indicators are located within a specified level of statistical significance $(p \leq 0.05)$. Taking into account the differences between the various areas of life before and after the surgery, only daily life and sexual life after the treatment proved to be statistically significant $(p<0.05)$. Pain intensity decreased more than 5.5-fold. Before the operation treatment pain defined on the NRS scale was 7.72 on average, while $50 \%$ of the respondents (25 people) indicated the highest degrees of intensity of pain (8-10). The period immediately after the operation did not change diametrically the perceived level of pain, because after a month the average was still high (5.2). However, even then 37 (73\%) patients indicated that the pain was at the level 4-5. Two months were a turning point, since the average decreased by about a half, reaching a level of 3.34. The following months saw a small change, and the average decreased to the level of 2.14, and after a year it was 1.4 . Five people $(10 \%)$ still felt pain at level 3 on the NRS. It can be concluded that the surgery significantly reduces the level of pain. It does not occur radically, but in a gradual and systematic way. The evaluated indicators are within the specified range of statistical significance $(p \leq 0.05)$. Almost all of the respondents declared that they did not have any problems in performance of daily care of themselves (92\%). This means that the haemorrhoid disease allows them to maintain a high degree of independence and does not force patients to involve the close family for providing assistance. Although $4(8 \%)$ people noted some problems with the performance of primary daily care, they do not engage third parties. Evaluated indicators are not within the specified range of the level of statistical significance $(p \leq 0.05)$ and thus they are not statistically significant. The majority of respondents stated that there are no problems with the performance of daily tasks (74\%), and none of the people surveyed found that these activities pose an insurmountable barrier. Thirteen people noted that there were problems with everyday tasks, but they could deal with them. Evaluated indicators are statistically significant, as they are within the specified range of the level of statistical significance $(p \leq 0.05)$. The examined patients answered that they felt pain or felt badly after the undergone treatment (80\%), but none of the respondents marked the answer 'I feel pain, it is difficult to bear'. Also in this case the re- 
sults are statistically significant $(p \leq 0.05)$. Most of the respondents declared that they did not feel anxiety or depression, and only 17 (34\%) patients occasionally had feelings of anxiety $(p \leq 0.05)$. On a scale similar to a thermometer the respondents indicated their best health that they could imagine as the number 100, and the worst health status as 0 . The vast majority of surveyed patients (30 people $60 \%$ indicated their health condition with a number from 80 to 100 . These data suggest that this kind of surgery was a good solution to elevating the health status assessment. Twelve (24\%) patients marked the assessment of their state of health below 60 . It seems that this may be due to age and other comorbidities and appears in adulthood. The indicators are also within the specified range level of statistical significance $(p \leq 0.05)$.

On the basis of the survey it can be concluded that patients are able to identify characteristic symptoms of haemorrhoidal disease, and most often indicate the appearance of blood in bowel movements $(100 \%)$, feeling of incomplete bowel movement $(100 \%)$, the two results are not statistically significant and palpable nodules palpable lumps in the perineal area $(78 \%)$ indicator statistically significant $p<0.05$. There are three basic factors affecting the development of haemorrhoids: pregnancy (76.2\%), overweight (76\%) and sitting work (44\%). Our respondents are supplementing the knowledge about correct feeding, only $6 \%$ of them showed no source of knowledge. The perception of pain is very diverse and individual and, of course, with increasing time from the surgery its strength decreases. Average pain decreases within a year from the operation 5.5 -fold (from 7.72 before the surgery to 1.4 after the surgery). The results obtained are within a certain range of statistical significance $(p \leq 0.05)$. The operated patients indicate significant differences in daily life before and after surgery. The results are statistically significant $(p<0.05)$. The respondents are satisfied with their lives after the surgery, and $60 \%$ of them expressed their health with a number from 80 to 100 . The results are statistically significant $(p<0.05)$.

\section{Conclusions}

Based on the survey, it was found that the haemorrhoid disease is more common in women (84\%) than in men. The patients exhibit the basic risk factors for the occurrence of haemorrhoids: sitting at work (44\%), and low physical activity, which leads to overweight (76\%). People suffering from haemorrhoids can indicate the characteristic symptoms of the disease; the main ones are the appearance of blood in bowel movements (100\%) and feeling of incomplete bowel movements (100\%). Also there is a feeling of anxiety and tension associated with the disease $(88 \%)$ and pain in the case of changing position (86\%). The results for the appearance of blood in bowel movements and feeling of incomplete bowel movements are not statistically significant. The group of examined patients indicated differences in daily life before and after surgery. The health status improved, according to respondents, to the greatest extent in terms of household chores such as cleaning, cooking (92\%) and in terms of social life (86\%) and paid work $(80 \%)$. In the slightest degree the state of health improved in the issues of everyday and family life (68\%) and sexual life (46\%). Derived indicators are statistically significant $(p \leq 0.05)$. Operated patients are able to differentiate and evaluate pain, both before surgery and in the later period of time. The indicators are within the specified range level of statistical significance $(p \leq 0.05)$. Patients filling in the questionnaire can assess their quality of life and health. Most of the respondents stated that there are no problems with mobility, and the vast majority do not have any problems with the care of oneself (92\%). Most respondents also claimed that there are no problems with the performance of daily tasks (74\%), and none of the people found that these activities are for them an insurmountable barrier, due to the pain. Most of the examined patients claimed that they do not feel anxiety or depression $(66 \%)$. The indicators are within the specified range level of statistical significance $(p \leq 0.05)$. The indicators are statistically significant because they are within a certain range of statistical significance $(p \leq 0.05)$. The patients estimated their health on the basis of a scale similar to a thermometer, the best score being 100, while the worst is 0 . A considerable majority of patients indicated on the scale the result from 70 to 90 . The average health status for the whole group was 72 , which should be considered as a good health status after the surgery. The indicators are within the specified range level of statistical significance $(p \leq 0.05)$.

On the basis of the study it can be concluded that Ferguson's method using the LigaSure apparatus is an effective method in the treatment of hae- 
morrhoidal disease, contributing to a significant improvement in the quality of life in many of its areas.

\section{Conflict of interest}

The authors declare no conflict of interest.

\section{References}

1. Haes PA, Fox TA, Haas GP. The pathogenesis of haemorrhoids. Dis Colon Rectum 1984; 27: 442-50.

2. Godeberge P. Atlas of diseases of the blood nodules. Medical Publication Polish Server 2004; 8-97.

3. Gaj F, Trecca A, Crispino P. Haemorrhoid disease during preg nancy: focus on delivery unit. Clin Ter 2007; 158: 285-9.

4. Banaszkiewicz Z, Jankowski M, Jawień A. The blood disease of the rectum. Przew Lek 2003; 10: 84-7.

5. Becker F. Venous pathology. Via Medica, Gdansk 2006; 27-139.

6. Cabaj H. Hemorrhoidal disease. Health Service 2002; 15-18: 38-40.

7. Bielecki K, Cabaj H. Hemorrhoidal disease. The Progress of Medical Science 2000; 3: 35-8.

8. Krasowski G, Kruk M. Hemorrhoids. PZWL, Warsaw 2005; 11-68,

9. Dziki A, Trzciński R. Hemorrhoidal disease. Health Service 1999; 87-88: 27-31

10. Matławska I. Plant medicines in the treatment of hemorrhoidal disease. The World of Medicine and Pharmacy 2005; 5: 27-30.

11. Dyczkowski K, Pawełczyk I, Starzewski J. Hemorrhoids and what's next. Primary Care Doctor 2004; 7: 100-3.

12. Łazowski J. Żylaki odbytu. Farmacja Polska Poradnictwo w Samoleczeniu 1999; 19: 876-9.

13. Trzciński R, Dziki A. If everything we already know about hemorrhoids. Proctology 2000; 1: 7-16.

14. Michalak J, Wolski A. Hemorrhoidal disease. Family Medicine 2001; 2: 61-3.

15. Wolski A. Pathophysiology of blood nodules. Medycyna Ogólna - Problemy Pracy Lekarza Rejonowego i Zdrowie Populacji 1996; 2: 100-10.

16. Friediger J, Borycka-Wąsik K. The disease of blood tumor. Poland Pharmacy 2004; 4: 528-35.

17. Gryglewski A, Kosowski K. Treatment of blood the tumor. Res Med 2006; 5: 299-303.

18. Kościński T, Malinger ST, Matysiak K. Today's treatment options for hemorrhoidal disease. Pol J Surg 2000; 9: 857-60.

19. Szyca R, Leksowski K, Dratwa S, et al. Operational treatment of the disease blood nodules using a system of sealing Liga Sure. Valetudinaria 2004; 1: 9.

20. Michalik M, Budziński R, Świątczak Z. Operations of hemorrhoids of way Longo. Pol J Surg 1999; 6: 601-3.

21. Szyca R, Dratwa S, Tomaszewski S, Leksowski K. Operational treatment of hemorrhoids with the use of the camera Liga Sure. Proktologia Supplement 2006; 2: 45.

22. Singer $M$, Clinton J. New methods for the treatment of perianal diseases. Chirurgia po Dyplomie 2007; 6: 63-71.

23. Wysocki W, Bała M. Hemorrhoidectomy using diatermii in comparison with the application of LigaSure. Netfirms-Surgery 2007; 6: 113-5.
24. Pesta W, Wirkowski A, Leksowski K. Stapled haemorrhoidopexy for the treatment of haemorrhoids: a review of our experience. Videosurgery Miniinv 2009; 4: 147-53.

25. Szyca R, Aniukiewicz K, Ostrowski C, Leksowski K. Treatment of diseases of the blood nodules way Barron with simultaneous Cryo therapy - prospective study. Proctology 2006; 7: 194-9.

26. Duben J, Hnatek L, Dudesek B, et al. Bipolar radiofrequency-induced thermotherapy of haemorrhoids: a new minimally invasive method for haemorrhoidal disease treatment. Early results of a pilot study. Videosurgery Miniinv 2013; 8: 43-8.

Received: 14.04.2014, accepted: 18.01.2015 